\section{A Rare Non-obstetric Pathology in Pregnancy: Obstructive Sigmoid Colon Cancer}

Sir,

Colorectal cancer is a rare condition in pregnancy with reported incidence of 8 per million. ${ }^{1}$ Constipation, abdominal pain, vomiting, intermittent rectal bleeding and anemia, are frequently seen in pregnancy. Furthermore, these are also common in colorectal cancers. ${ }^{2}$ Because of these, the diagnosis of colorectal cancer in pregnancy may be delayed. ${ }^{3}$

A 37-year woman with a 17-week pregnancy (in vitro fertilisation; gravida 1, para 1) consulted the clinic with abdominal pain, periumbilical cramps, distention, vomiting and constipation complaints, which she had for the last 8 days. The patient had no family history and any known diseases. Previously, she had complaints of constipation and distension for 10 months. Colonoscopy was recommended, but she refused due to pregnancy. The patient's examination revealed extensive abdominal distension and increased bowel sounds. The vital findings were normal. Laboratory values were normal except for leukocytosis and an increased in C-reactive protein (CRP). In fetus-guarded standing direct abdominal X-ray, there was an appearance of dilated bowel loops up until the left colon (Figure 1a). An abruptyended dilated bowel loop was observed on magnetic resonance imaging (MRI) without contrast (Figure 1b). The patient was recommended sigmoidoscopy, but she refused it. Exploratory laparotomy was performed on the same day. There was a fully obstructive tumor in the sigmoid colon. End-colostomy was opened with sigmoid colon resection. In pathologic examination, there was 6 $\mathrm{cm}$ tumor consistent with moderately differentiated adenocarcinoma of the sigmoid colon. There were 23 lymph nodes, with metastasis in 8 of them. Fetus was assessed as normal in the postoperative period. The patient was referred to the oncology clinic for adjuvant treatment.

Pregnancy can limit the use of standard diagnostic and therapeutic tools. While abdominal ultrasonography and MRI can be used safely, computerised tomography should not be used because of the high radiation dose for the fetus.3,4 Endoscopic evaluation can be used in pregnancy as another diagnostic method.

The treatment of colorectal cancer is not different in terms of pregnant patients, but it may vary with the stage, localisation, and urgency of the cancer and gestational

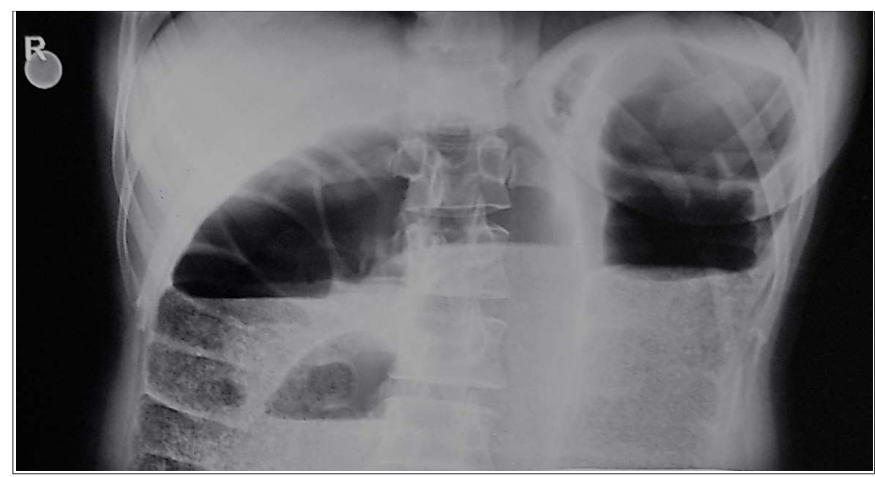

Figure 1a: Standing direct abdominal X-ray

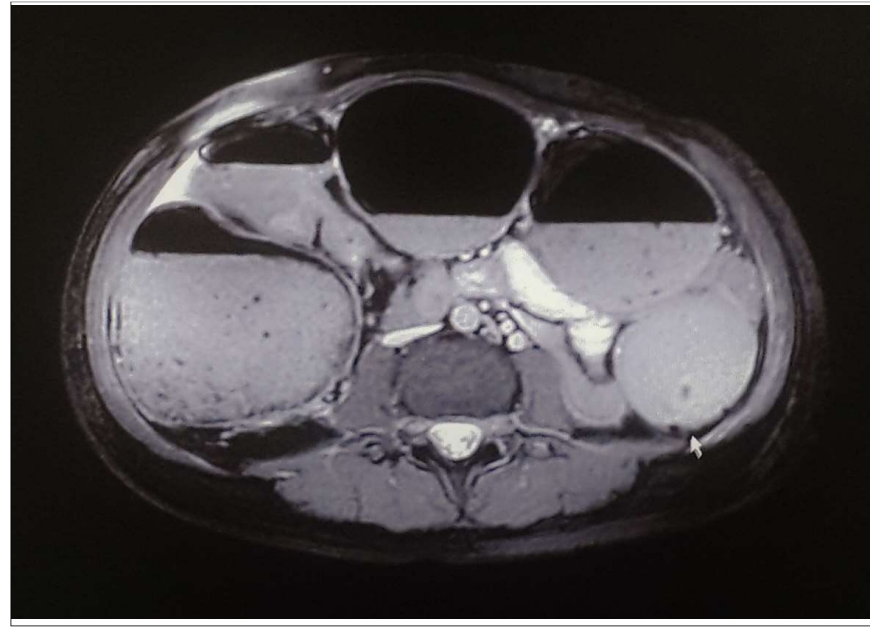

Figure 1b: MRI of abdomen without contrast

duration. Surgical treatment should be performed without delay in order to prevent the progression of the disease stage before the adjuvant treatment. After delivery, treatment should continue according to standard colorectal cancer guidelines. 5 While performing all of these, the fetal health should be considered.

Since symptoms of normal pregnancy and cancer are similar, there is usually a delay in the diagnosis of later. Endoscopy and MRI can be used safely. Treatment of pregnant colorectal cancer patients should be individualised till the end of pregnancy.

\section{REFERENCES}

1. Lee YY, Roberts CL, Dobbins T, Stavrou E, Black K, Morris J, et al. Incidence and outcomes of pregnancy-associated cancer in Australia, 1994-2008: A population-based linkage study. BJOG 2012; 119:1572-82.

2. Jones A, Povlow MR. Colorectal cancer presenting with constipation during pregnancy. Cureus 2017; 9:1-4.

3. Kocián P, de Haan J, Cardonick EH, Uzan C, Lok CAR, Fruscio $\mathrm{R}$, et al. Management and outcome of colorectal 
cancer during pregnancy: Report of 41 cases. Acta Chirurgica Belgica 2018; 1-10.

4. De Haan J, Vandecaveye V, Han SN, Van de Vijver KK, Amant F. Difficulties with diagnosis of malignancies in pregnancy. Best Pract Res Clin Obstet Gynaecol 2016; 33:19-32.

5. Erman Aytac, Gokhan Ozuner, Ozgen Isik, Emre Gorgun, Luca Stocchi. Management of colorectal neoplasia during pregnancy and in the postpartum period. World $J$ Gastrointest Oncol 2016; 8:550-4.
Hasan Calis and Sidki Cetin

Department of General Surgery, Faculty of Medicine, Alanya Alaadin Keykubat University, Alanya-07400, Turkey

Correspondence: Dr. Hasan Calis, Department of General Surgery, Faculty of Medicine, Alanya Alaadin Keykubat

University, Alanya-07400, Turkey

E-mail:drhasancalis@hotmail.com

Received: November 27, 2018; Revised: February 01, 2019; Accepted: February 01, 2019

.......... 